\title{
Full Mouth Rehabilitation of a 12-year-old Patient with Hidrotic Ectodermal Dysplasia with Removable Partial Denture: a CASE Report
}

\author{
Maryam Azimi Zavaree ${ }^{1}$, Ehsan Morshedi ${ }^{2}$ and Seyed Mohammad Reza Hakimaneh*1 \\ ${ }^{1}$ Department of Prosthodontics, Faculty of Dentistry, Shahed University, Iran \\ ${ }^{2}$ Department of Prosthodontics, Faculty of Dentistry, Zanjan University of Medical Sciences, Iran
}

Received: March 07,2018; Published: April 06, 2018

*Corresponding author: Seyed Mohammad Reza Hakimaneh, Faculty of Dentistry, Shahed University, 1417755351 West Italia St, Vesal Shirazi Ave, Keshavarz Blvd, Tehran, Iran, Tel: 00989131144339; Email: rezahakimaneh@gmail.com

\begin{abstract}
Aim: The aim of this study was to rehabilitate a 12-year-old patient with hidrotic ectodermal dysplasia with removable partial denture.

Background: Ectodermal dysplasia (ED) is a hereditary disorder with abnormal ectodermal tissues. Most common oral findings include hypodontia and anodontia. Treatment options include removable partial denture (RPD), complete denture (CD), overdenture (OD) and implant supported prosthesis. Choosing a treatment plan is dependent on the age, growth pattern, and functional, biomechanical and esthetic demands of the patient with regard to save anatomy of the patient especially because the affected individuals are young.
\end{abstract}

Case Description: A 12-year-old boy with hidrotic ED that was formerly treated with RPD was referred to Shahed dental school to receive a new prosthesis. He had only 8 existing teeth. After making the primary and final impressions, the centric relation was registered, the teeth were arranged and the denture was processed and delivered.

Conclusion: The removable partial denture is still one of the treatment approach for treatment of patients with hidrotic ED.

Clinical Significance: The removable partial denture could be successful in treatment of young patients with hidrotic ED.

Keywords: Ectodermal Dysplasia; Removable Partial Denture; Full-Mouth Rehabilitat

Abbreviations: ED: Ectodermal Dysplasia; RPD: Removable Partial Denture; CD: Complete Denture; OD: Overdenture

\section{Background}

Ectodermal dysplasia (ED) are a group of complex congenital disorders that involved 2 or more embryonic ectodermal layers derivate structures such as skin, hair, nails, nerve cells, sweat glands and parts of the eye and ear [1,2]. ED has two major types:

a) Hypohidrotic or Anhidrotic that the number of sweat glands is decreased or they are absent or they have abnormal function.

b) Hidrotic in which the sweat glands are normal [3].

Hypohidrotic ED is an x-linked autosomal recessive hereditary disorder [4]. In ED patients there are multiple abnormalities in oral findings such as anodontia, hypodontia, malformed and widely spaced peg like teeth, loss of occlusal vertical dimensions, protuberant lips, underdeveloped alveolar ridges and collapsed bite [3,5-7].Transverse bone growth and sagittal maxillary and mandibular growth would be affected by absence of teeth as a result of hypodontia and reduced alveolar ridge impacts on vertical growth [8]. Thus ED patients usually require multidisciplinary approach in dental rehabilitation which should be started in younger ages ideally [4].

The prosthodontic rehabilitation of ED patients should be based on patient's growth and developmental characteristics. Different treatment approaches have been reported that include single crowns, fixed partial dentures (FPD), complete dentures (CD), removable partial dentures (RPD), overdentures (OD) and implant retained prostheses [9]. The young patients with ED were often treated by removable prostheses [10]. However for choosing the most appropriate type of removable prostheses there is no systematic review [9]. The purpose of this case report was to explain the treatment of young patient with ED to return mastication, appearance, social and psychological health. 


\section{Case Description}

A 12-year-old male patient with hidrotic ED was referred to the department of prosthodontics, dentistry faculty of Shahed University. A former RPD treatment was done for him at the age six at the same place. His chief complaint was lack of retention of the RPD. No abnormality in the ectodermal derived tissues was seen in clinical evaluations, except hypodontia due to minor expressions of the hidrotic type of ED. In oral examinations just all E milk teeth and first permanent molars were present. These were the teeth he had from the first visit at age six and they were saved in a good condition during the past six years (Figures $1 \& 2$ ).

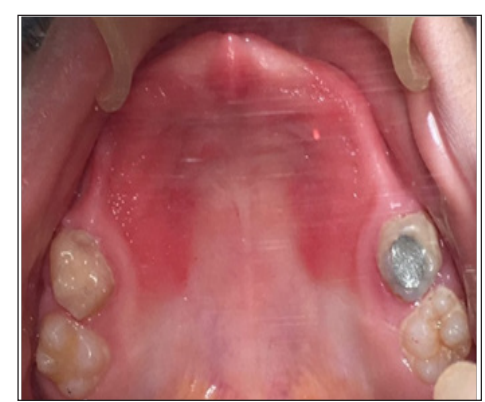

Figure 1: The maxillary arc.

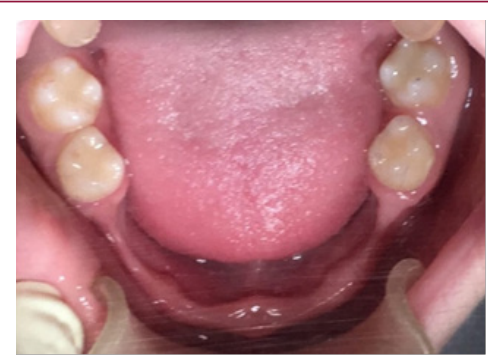

Figure 2: The mandibular arc.

Regular follow ups were done every 6 to 8 months and adjustments and even chairside hard relining was done if required during this six year follow up to set with the growing alveolar process. Radiographic findings revealed a thin alveolar process in edentulous areas. Permanent teeth buds of second molars and second premolars were present as well.

After a brief consultation with Oral and Maxillofacial Surgery, Periodontology and Pediatrics departments and arguing between fabricating a new RPD and implant supported OD, continuing the present treatment with a new RPD was chosen. Bone grafting was obligatory for implant supported OD treatment plan. Lack of enough donor sites for the final implant supported treatment at patient's adolescence while the patient's growth is almost done and infra occlusion osseointegrated implants were concerns that made us chose RPD instead of an implant supported OD at this time. A primary impression with putty and wash (Panasil Putty Soft \& Initial Contact X-Light Kettenbach GmbH \& Co. KG-Germany) and a plastic stock tray was made in a two stage impression technique to fabricate a special tray. Border molding was done with low fusing modeling compound (Kerr green stick impression compound - Germany) and final impression was made with regular body additional silicone in a single phase impression technique (Panasil monopren Kettenbach GmbH \& Co. KG-Germany).
Base and wax rim adjustment was done respecting the occlusal plane, vertical dimension of occlusion, facial support and esthetics. Centric relation and facebow records were registered and transfer to a nonarcon semiadjustable articulator (Dentatus ear bow type AEE \& articulator type ARH, Stockholm, Sweden) Upper incisors were chosen from permanent mold and other teeth from primary denture teeth mold. Try in session was done with the presence of the patient parents. A retentive clasp was added in the final prosthesis located on all "D" primary teeth for retention (Figures 3a \& 3b). Dentures were remounted, adjusted and polished prior to delivery.

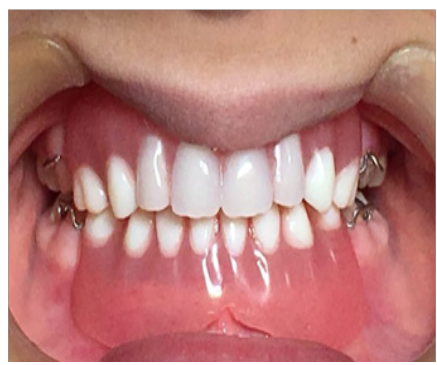

Figure 3a: RPD in the mouth.

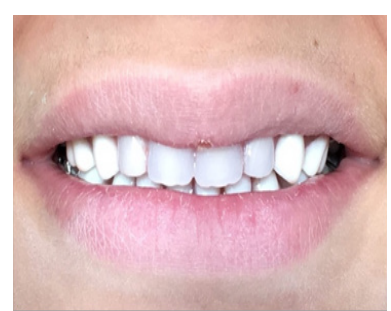

Figure 3b: The frontal view of the RPD in the mouth.

Patient and his parents were instructed during delivery session and 4 follow up visits were performed at the day after delivery and the next 2 weeks. Parents were instructed for the regular recalls every 6 months as well.

\section{Discussion}

Dental anomalies and facial appearance is the most common complaint of patients with ED and their treatment is a challenging task especially in the pediatric patients [11]. One of the problems is periods of rapid growth in children patients so the treatment of choice is often a removable partial denture or complete denture that could be easily modified [10]. According to Maroulakos et al. study there is an algorithm that guided the process of treatment decision-making. In this algorithm there are several factors that should be considered such as presence of posterior natural teeth, facial aesthetics and lip support, number and size of existing natural teeth and occlusal vertical dimension [6]. RPD would be the best option in presence of natural teeth [12], such as our case that has all E primary teeth and first permanent molars without any anatomical and morphological abnormalities.

Pretreatment extra oral aesthetic evaluation of the patient is very important. These patients often characterized by inadequate facial aesthetics because of improper lip support so the use of prostheses with the anterior denture flange would be a more appropriate treatment option [13]. For successful treatment 
outcome regular follow up of ED patients is needed. There are several factors that compromise the prosthetic outcome such as poor retention and stability, progressive alveolar bone resorption, improper oral hygiene, periodontal/soft tissue complications and increased caries rate $[13,14]$. To reduce complications patients and their parents should be trained to know possible problems and maintenance of prostheses [6]. In our case periodic recalls had been done. There is a guideline that recommends relining/ rebasing intraoral prosthesis in a growing patient every 2-4 years and remaking a new prosthesis after 4-6 years [14].

There are some alternative treatment options such as the use RPD/OD prostheses [15], magnets [12], ODs with windows to accommodate erupting posterior teeth [16] and dental implants. Since dental implants cannot follow the alveolar bone growth and become ankylosed, they are only indicated in the anterior mandible of ED patients who are older than 12 years old [17]. In children with ED there are limited options for treatment because of the remaining growth. So the most common choice is OD or RPD and the parameters for choosing one of them are the presence of posterior natural teeth, facial aesthetics, lip support, number and size of existing natural teeth and the occlusal vertical dimension.

\section{Conclusion}

The removable partial denture is still one of the treatment approaches for treatment of patients with hidrotic ED.

\section{Clinical Significance}

The removable partial denture could be successful in treatment of young patients with hidrotic ED.

\section{References}

1. Koyuncuoglu CZ, Metin S, Saylan I, Calısir K, Tuncer O, et al. (2014) Full-Mouth Rehabilitation of a patient With Ectodermal Dysplasia with Dental Implants. Journal of Oral Implantology 40(6): 714-721.

2. Shigli A, Reddy RP, Hugar SM, Deshpande D (2005) Hypohidrotic ectodermal dysplasia: a unique approach to esthetic and prosthetic management: a case report. Journal of the Indian Society of Pedodontics and Preventive Dentistry 23(1): 31-34.

3. Rad AS, Siadat H, Monzavi A, Mangoli AA (2007) Full mouth rehabilitation of a hypohidrotic ectodermal dysplasia patient with dental implants: a clinical report. Journal of prosthodontics 16(3): 209-213.

4. Guler N, Cildir S, Iseri U, Sandalli N, Dilek O (2005) Hypohidrotic ectodermal dysplasia with bilateral impacted teeth at the coronoid process: a case rehabilitated with mini dental implants. Oral surgery, oral medicine, oral pathology, oral radiology, and endodontics 99(5): E34-38.

5. Wu Y, Zhang C, Squarize CH, Zou D (2015) Oral Rehabilitation of Adult Edentulous Siblings Severely Lacking Alveolar Bone Due to Ectodermal Dysplasia: A Report of 2 Clinical Cases and a Literature Review. Journal of oral and maxillofacial surgery 73(9): 1733e1-1733e12.

6. Maroulakos G, Artopoulou, Angelopoulou MV, Emmanouil D (2015) Removable partial dentures vs overdentures in children with ectodermal dysplasia: two case reports. European archives of paediatric dentistry 17(3): 205-210.

7. Li D, Liu Y, Ma W, Song Y (2011) Review of ectodermal dysplasia: case report on treatment planning and surgical management of oligodontia with implant restorations. Implant dentistry 20(5): 328-330.

8. Guckes AD, Scurria MS, King TS, McCarthy GR, Brahim JS (2002) Prospective clinical trial of dental implants in persons with ectodermal dysplasia. The Journal of prosthetic dentistry 88(1): 21-25.

9. Artopoulou, Martin JW, Suchko GD (2009) Prosthodontic rehabilitation of a 10-year-old ectodermal dysplasia patient using provisional implants. Pediatric dentistry 31(1): 52-57.

10. Hickey AJ, Vergo TJ, (2001) Prosthetic treatments for patients with ectodermal dysplasia. The Journal of prosthetic dentistry 86(4): 364368.

11. Siegel MB, Potsic WP (1990) Ectodermal dysplasia: the otolaryngologic manifestations and management. International journal of pediatric otorhinolaryngology 19(3): 265-271.

12. Rockman RA, Hall KB, Fiebiger M (2007) Magnetic retention of dental prostheses in a child with ectodermal dysplasia. Journal of the American Dental Association 138(5): 610-615.

13. Bidra AS, Martin JW, Feldman E (2010) Complete denture prosthodontics in children with ectodermal dysplasia: review of principles and techniques. Compendium of continuing education in dentistry 31(6): 426-433.

14. Vergo TJ (2001) Prosthodontics for pediatric patients with congenital/ developmental orofacial anomalies: a long-term follow-up. The Journal of prosthetic dentistry 86(4): 342-347.

15. Della Valle D, Chevitarese AB, Maia LC, Farinhas JA (2004) Alternative rehabilitation treatment for a patient with ectodermal dysplasia. The Journal of clinical pediatric dentistry 28(2): 103-106.

16. Dalloca S, Ceppi E, Pompa G, Polimeni A (2008) X-linked hypohidrotic ectodermal dysplasia: a ten-year case report and clinical considerations. European journal of paediatric dentistry 9 (4 Suppl): 14-18.

17. NFED scientific Advisory Board (2003) Parameters of Oral Health Care for Individuals Affected by Ectodermal Dysplasia Syndromes, Mascoutah, IL. National Fountation for Ectodermal Dysplasias.

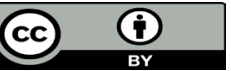

This work is licensed under Creative Commons Attribution 4.0 License

Submission Link: https://biomedres.us/submit-manuscript.php

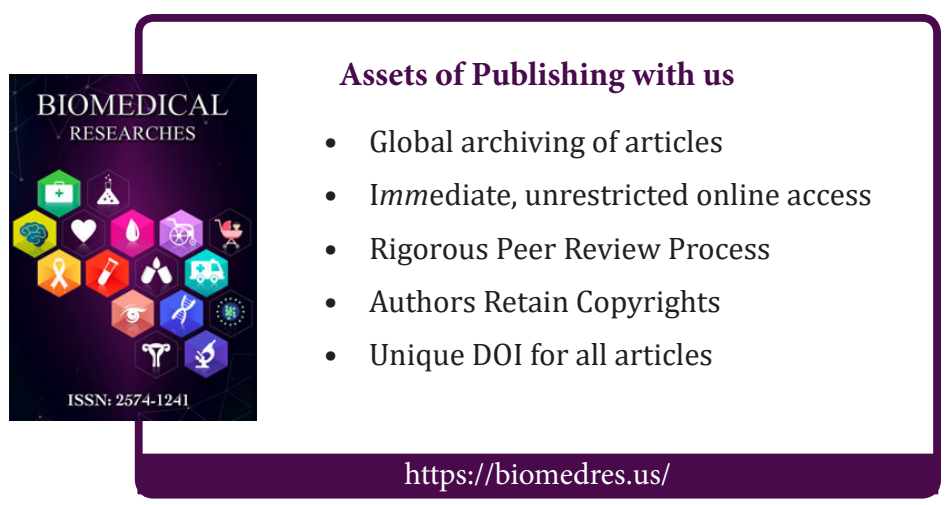

